\title{
HOBSBAWM Y EL SIGLO XX. A PROPÓSITO DE AGE OF EXTREMES
}

\author{
Roy Hora \\ Master of Studies, University of Oxford. \\ Candidato Doctoral, St Antony's College, Universidad de Oxford.
}

RESUMO: Este artigo analisa o livro Age of Extremes, de Eric Hobsbawm. O livro é discutido no contexto da visão que Hobsbawm oferece da história mundial dos séculos XIX y XX. Os compromissos políticos e intelectuais de Hobsbawm são também considerados para entender sua visão da história contemporânea mundial.

PALAVRAS-CHAVE: Hobsbawm, história mundial, historia siglo XX, intelectual comunista, marxismo.

ABSTRACT: This essay analyses Age of Extremes, Eric Hobsbawm's last book. Age of Extremes is discussed in the context of Hobsbawm's approach to XIX and XX century world history. Hobsbawm's intellectual and political commitments are also taken into consideration in order to understand the way in which he examines and describes modern world history.

KEYWORDS: Hobsbawm, world history, XX century history, comunist intelectual, marxism.

La obra de Eric John Hobsbawm ha tenido una influencia muy notoria entre los historiadores y los científicos sociales del mundo anglosajón formados desde la década del sesenta. En América Latina los trabajos de Hobsbawm han dejado una marca no menos persistente. Las razones sin duda están a la mano. Desde fines de los años cincuenta, Hobsbawm publicó un conjunto sorprendentemente vasto de ensayos y trabajos que pronto ganaron la atención no sólo de los historiadores sino también del mundo in- telectual de izquierda a ambos lados del Atlántico. El primero de ellos fue Primitive Rebels. Aparecido en 1959, Rebeldes Primitivos llamó la atención sobre las formas de protesta y rebelión del mundo campesino o preindustrial en contextos sociales de transición al capitalismo. Fue quizá este trabajo, traducido al castellano en 1968, aquel que lo hizo conocido -y discutido- en Latinoamérica, dada la relevancia de las rebeliones "arcaicas" en el clima político y las discusiones intelectuales de esos años en muchas 
regiones de América del Sur. Hobsbawm continuó la exploración de esta forma de protesta social en Bandits (1969). ${ }^{1}$

A esta reflexión sobre las formas de protesta y conflicto en sociedades campesinas y preindustriales la antecedía otra preocupación, más clásica, por la historia del trabajo y la clase obrera, que el joven Hobsbawm comenzó a desarrollar con una serie de publicaciones surgidas en la posguerra del ya casi mítico Grupo de Historiadores del Partido Comunista Británico y una tesis doctoral sobre el fabianismo inglés. ${ }^{2}$ En los sesenta, esta línea de investigación tomó cuerpo y dio lugar a la compilación de artículos conocida como Labouring Men (1964), y a Captain Swing (escrito en colaboración con George Rudé, y aparecido en 1969). Ambos agregaron capítulos notables a la historia del movimiento obrero y del mundo del trabajo urbano y rural inglés, abonando, de varias maneras, un campo que iba a ser fuertemente impactado por la publicación de la gran obra de Edward Thompson, The Making of the

\footnotetext{
${ }^{1}$ Es conveniente señalar que la contribución de Hobsbawm a los estudios sobre campesinado ha estado en el centro de varios debates (CORRIGAN, 1975). Una serie de viajes a América del Sur en los años sesenta, algunos de ellos motivados por su actividad de militancia comunista, le permitieron a Hobsbawm dedicar cierta atención al campesinado latinoamericano, más específicamente al de Colombia y Perú (HOBSBAWM, 1967 a y b, 1969, 1974, 1976). Pero parece razonable concluir que en América Latina el impacto de estos estudios ha sido menor que el interés despertado por sus trabajos sobre la política "arcaica". Por razones en gran medida ligadas a las peculiaridades de la historia de sus clases subalternas, tal vez fue Brasil el país donde los trabajos de Hobsbawm sobre la protesta primitiva despertaron un interés más vivo. Sin embargo, es importante señalar que la influencia de la obra de Hobsbawm en Latinoamérica se ha dado de muchas maneras, aunque su contribución todavía no ha sido objeto de estudio sistemático. Hilda Sabato ha ofrecido recientemente
}

English Working Class. En esos años, Hobsbawm hizo también una contribución mayor a la historia socioeconómica del surgimiento y expansión del capitalismo británico; como visión de conjunto, su Industry and Empire (1968) todavía hoy resulta difícilmente superable. Tiempo antes, en 1954, su conocido ensayo sobre la crisis general del siglo XVII ya había incorporado al marxista inglés a la gran discusión sobre la transición del feudalismo al capitalismo.

Más recientemente, en los años ochenta, Hobsbawm ha vuelto a hacerse notar por sus contribuciones sobre la "invención de las tradiciones" y sobre las naciones, el nacionalismo y la tradición revolucionaria francesa. Así, pues, a su renombre surgido en el campo de la historia del trabajo y las clases subalternas, Hobsbawm sumó posteriormente, con The Invention of Tradition (editado con Terence Ranger en 1983), Nations and Nationalism since 1780 (1990), y Echoes of the Marsaillese (1990), amplio reconocimiento como estudioso de los fenómenos culturales. Una rápida ojeada a esta producción más reciente permite obser-

algunas reflexiones sobre la apropiacion de Hobsbawm en Argentina (SABATO, 1993). The Varieties of Latin American Banditry (SLATTA, 1987) y discusiones más recientes sobre el bandismo social muestran todavía la vitalidad de los problemas abiertos por el pequeño libro escrito por Hobsbawm en 1969.

${ }^{2}$ El Grupo de Historiadores del Partido Comunista de Gran Bretaña funcionó entre 1946 y 1956. Entre esos años, reunió a un brillante grupo de historiadores afiliados a dicho partido: Maurice Dobb, Rodney Hilton, Christopher Hill, George Rudé, Victor Kiernan, John Saville, el propio Hobsbawm, y, en menor medida, Edward Thompson. Entre el esfuerzo editorial del Grupo se cuenta la colección de documentos Labour's Turning Point, 1880-1900, editada y prologada por Hobsbawm. Los conflictos desatados dentro del comunismo británico por la invasión soviética a Hungría en 1956 virtualmente le pusieron fin al Grupo, así como a la pertenencia de muchos de sus integrantes al partido. Hobsbawm, sin embargo, permaneció dentro del PCGB (KAYE, 1984). 
var como en el curso de tres décadas Hobsbawm ha venido renovando sus preguntas e inquietudes: de la discusión sobre los orígenes y la dinámica del capitalismo, de la interrogación por los procesos de constitución de las clases subalternas y por sus prácticas asociativas y políticas, el historiador inglés ha girado su atención hacia las dimensiones simbólicas de la realidad social, acompañando de este modo una deriva más general de la historiografía mundial. Conviene señalar la peculiaridad de este giro de Hobsbawm, que por momentos se asemeja a una vuelta a sus intereses primeros. Pues a este historiador inglés - al fin y al cabo, un digno hijo de la burguesía ilustrada centroeuropea- el campo de la historia cultural nunca le había sido ajeno. No sólo porque Hobsbawm, todavía como estudiante de grado en Cambridge, había hecho sus primeras armas como comentarista cinematográfico en publicaciones de circulación universitaria; más fundamentalmente, porque había incursionado firmemente desde los cincuenta como crítico e historiador de la música popular. Con el seudónimo de Francis Newton, en esos años Hobsbawm escribió una serie de ensayos sobre jazz - pero también sobre temas que van de la rumba a Bob Dylan- aparecidos en New Statesman, así como su libro The Jazz Scene (1959). Además de todo ello, Hobsbawm es también un historiador del marxismo y un conocedor de la obra de Marx, editor de The History of Marxism y recordado por su renovador prólogo a las Pre Capitalist Economic Formations. ${ }^{3}$

Prodigiosamente amplia, escrita con maestría e impecable erudición, la obra de Hobsbawm sin em-

\footnotetext{
${ }^{3}$ Una exhaustiva bibliografía de la obra de Hobsbawm hasta comienzos de los años ochenta ha sido confeccionada por Keith McClelland (McCLELLAND, 1984). Sobre la producción posterior de Hobsbawm, además de los trabajos ya mencionados, conviene señalar la compilación de ensayos políticos titulada Politics for a Rational Left (1988).
}

bargo no encuentra su núcleo en este ya de por sí vasto conjunto de trabajos. En cambio, es en sus volúmenes dedicados a la historia general del siglo XIX donde radican tanto su proyecto más ambicioso como sus mayores logros. Y tanto es así que resulta difícil precisar hasta qué punto nuestra comprensión de la historia europea y mundial de la etapa que va de 1789 a 1914 el "largo" siglo XIX- ha sido moldeada por la formidable trilogía que el comunista inglés publicó a lo largo de un cuarto de siglo. Sus tres volúmenes forman el corazón de lo que Perry Anderson ha calificado como "la más poderosa historia de la modernidad que actualmente poseemos" (ANDERSON, 1995). The Age of Revolution (1962) interpretó los años que van de 1789 a 1848 como una etapa de revolución social y cambio político, cuyo tema dominante fue la emergencia y el ascenso de la burguesía y los avances del capitalismo como nuevo sistema económico y social. Trece años más tarde, en 1975, Hobsbawm dio a conocer The Age of Capital, que analizaba el desarrollo de esas tendencias en las décadas centrales del siglo, a las que veía signadas por el triunfo silencioso de la burguesía en las principales naciones de Europa. Finalmente, en 1987 apareció The Age of Empire, focalizado en la expansión económica y política de las metrópolis capitalistas lanzadas a la conquista del globo.

En su conjunto, la obra de Hobsbawm, en especial su visión del siglo XIX, representa una de las cimas de la escritura histórica de la posguerra. En una época de creciente parcialización del saber, no resulta sencillo encontrar una obra que combine economía, política, sociedad y cultura con la destreza y seguridad que es habitual en los escritos de Eric Hobsbawm. Menos aun, que al mismo tiempo sea capaz de articular un relato cuyo alcance y poderes explicativos sean parangonables a la historia decimonónica narrada por este autor. Siempre atento a la especificidad de cada sociedad, al mismo tiempo que a la totalidad del proceso en cuestión, el relato hobsbawmniano del siglo XIX tiene un tema central y un eje articulador: 
la historia del capitalismo y de su formidable capacidad para transformar sociedades, de los conflictos y los cambios que su despliegue ha generado. Podría decirse, incluso, que todo el trabajo de Hobsbawm -que recorre el arco que va del siglo XVII al XX-tiene por telón de fondo el problema de los orígenes, desarrollo y expansión del capitalismo como un proceso de cambio social que, de la economía a la cultura, impacta todos las dimensiones de la vida social.

Para Hobsbawm, el largo siglo XIX asistió al surgimiento y la expansión en Europa de una civilización basada en la economía capitalista, y en un orden legal y constitucional liberal sobre el que se asentaba un sistema internacional de estados. La burguesía fue su clase típicamente hegemónica; el avance de la ciencia y el conocimiento, del progreso material y moral, su bandera y su objetivo. Por todo ello, para Hobsbawm, el siglo XIX no sólo admite la posibilidad de una historia mundial; el vigor de las tendencias universalizadoras desatadas en los países centrales también la impone como perspectiva general.

Hacia fines del siglo XIX, estas fuerzas arrolladoras se hallaban en camino de desplegarse plenamente. En el tono que signa a La era del imperialismo se advierte la serena admiración de Hobsbawm por los logros del mundo decimonónico, capaz de una acumulación formidable de riqueza y saber, de poder y sofisticación técnica. Y esa celebración de la dinámica renovadora de las sociedades construídas por la burguesía, acelerada en las décadas finales del "siglo largo", puede ser aun más plena para Hobsbawm pues entonces ella se ofrecía como el suelo de un futuro distinto y mejor. Pues al igual que los jóvenes autores del Manifiesto Comunista, en todos sus textos Hobsbawm traza una imagen del siglo XIX que se encuentra pautada por tendencias secularizadoras, igualitarias y progresistas de muy largo alcance, que se hunden en el pasado pero que fundamentalmente apuntan al futuro. Fueron ellas las que dieron lugar a los complejos político-culturales y los grandes movimientos obreros constituídos en la época de la Segunda Internacional, con sus solidaridades clasistas y sus aspiraciones anticapitalistas.

Son precisamente esas promesas de avance en el sentido de un socialismo que, como hijo pleno de la Ilustración, parecía encaminado a recoger la herencia del mundo decimonónico - promesas con las que Hobsbawm una y otra vez se identifica- las que el siglo XX parece haber frustrado de modo radical. Al cerrarse el siglo Hobsbawm no sólo advierte que nuestra época ha terminado por cuestionar severamente la posibilidad de orientar con firmeza las sociedades humanas por el camino de la igualdad. También ha hecho naufragar mucho de lo que el comunista inglés ve valioso en el mundo burgués del siglo XIX. Por todo ello, la historia del siglo XX que nos ha presentado recientemente Hobsbawm no puede ser sino el relato de la caída brutal de una civilización (HOBSBAWM, 1995). Como señaló Tony Judt, la historia de lo que Hobsbawm denomina la "Era de los Extremos" es la historia de una época -la que va de la Primera Guerra Mundial al derrumbe del sistema soviético- que ha llevado a su mayor esplendor el potencial material y cultural de progreso social preparado a lo largo de más de un siglo que por muchas razones merece ser calificado de excepcional, y finalmente lo ha desbaratado (JUDT, 1995, p.20).

Y es que para Hobsbawm no es sólo la desaforada victoria del capital a escala mundial - hoy avanzando sin obstáculos sobre Moscú y Pekín - la que signa este fin de siglo, ni la declinación de los grandes partidos de base y discurso clasistas que fueron los principales mecanismos para transformar hombres y mujeres en ciudadanos o actores políticamente activos en el mundo occidental, ni la defunción de las vanguardias estéticas, o la regresión a una barbarie guerrera que a principios de siglo parecía superada o inimaginable, las que dan la medida de esta tragedia. Es la combinación y la suma de todos 
estos elementos los que indican la verdadera dimensión de esta caída y esta traición.

Por muchas de estas razones, los motivos del pesimismo de Hobsbawm son comprensibles. Pero esta visión sombría no sólo es consecuencia de que el marxista inglés fue testigo de una época que se inició con promesas de progreso y culmina ingresando al siglo XIX a golpes de mercado. Quizá más que ello, también resulta de circunstancias biográficas. Hobsbawm fue y sigue siendo un actor de los dramas de este "siglo veinte corto" que termina con el opacamiento de los ideales a los que consagró su vida de intelectual comunista. Ello se advierte en el hecho de que escribir la historia del siglo XX es para Hobsbawm un proyecto vinculado a su propia biografía (el siglo corto, por otra parte, coincide prácticamente con la vida de este intelectual nacido en Alejandría en 1917, tres años después de que el Archiduque Francisco Fernando muriese asesinado en Sarajevo). Por ello contar la historia de nuestro siglo es, para Hobsbawm, un ejercicio de trabajo - de expansión, de rectificación - sobre su propia memoria política e histórica (y el resultado es, sin duda, su libro más personal y autobiográfico). En distintas ocasiones, el propio Hobsbawm se hace presente en el relato, en instantáneas que muchas veces se vinculan con su vida de militante comunista. Así lo vemos, en una tarde de invierno de 1930, como un alumno de escuela secundaria que en su camino a casa en Berlin es sorprendido por los periódicos que anuncian la llegada de Adolf Hitler a la Cancillería alemana. Más tarde aparece, ya como miembro del Partido Comunista, defendiendo la República en la Guerra Civil Española. Lo hallamos en los años cincuenta, en Moscú, descubriendo con sorpresa que el todopoderoso Stalin se revela, una vez embalsamado, un hombre extremadamente pequeño (menos de 1,6m de estatura). Hobsbawm también se retrata formando parte de las multitudes seducidas por los interminables discursos de Fidel Castro. Aparece, asimismo, junto al lecho de muerte de Oskar Lange, inquieto por la pregunta sobre si hubiese sido posible otro modelo de industrialización en la Unión Soviética, menos brutal, menos indiscriminado, menos costoso en términos de esfuerzos $\mathrm{y}$ vidas humanas.

Age of Extremes está organizado en tres partes, que periodizan etapas del desarrollo socioeconómico capitalista. Cada una de ellas tiene un tema dominante, y sobre ese fondo se articulan los detalles de un cuadro general que evidencia la amplitud de conocimientos que es típica de todos sus escritos. Al mismo tiempo, a esta estructura tripartita se le sobreimpone una narración centrada en los conflictos político-ideológicos del siglo, que Hobsbawm ve dominada por el enfrentamiento entre capitalismo y comunismo. En la primera parte, llamada la "Era de las Catástrofes", Hobsbawm analiza un período de guerras, crisis y revoluciones en el que ve derrumbarse el mundo del siglo XIX. Esas tres décadas de inestabilidad se inician con la Primera Guerra Mundial, cuyo origen relaciona con la competencia interimperialista. Sin embargo, Hobsbawm no investiga en profundidad en qué medida la etapa previa prepara ese desenlace, y en cambio prefiere subrayar como las transformaciones que la Guerra desata implican un punto de no retorno respecto de las formas de sociabilidad dominantes en el siglo que entonces ve cerrarse. De este modo, Hobsbawm le quita relevancia a aquellos desarrollos que, como en el caso del nacionalismo decimonónico, en especial el de las clases subalternas, ofrecen una imagen alternativa de la herencia que el siglo moribundo ofrecía al nuevo.

A Hobsbawm le interesa señalar el corte por sobre la continuidad. Es por eso que subraya como tras cuatro o cinco años de una carnicería sin igual, la civilización que resurgiría de la guerra no iba a ser la de antes. En primer lugar, porque de allí en más el siglo no puede concebirse disociado de un nuevo tipo de esfuerzo bélico tan central a su historia como cualitativamente distinto de los que el mundo había 
conocido hasta entonces. Y ello no sólo por la abundancia de los conflictos o las nuevas técnicas de destrucción puestas en juego. También porque de allí en más la guerra total comenzó a golpear con especial dureza a las poblaciones civiles que sostenían el enorme esfuerzo que acarrean los nuevos conflictos. Un primer anticipo de esta nueva situación lo ofrece la prolongada y desgastante Primera Guerra Mundial. La Gran Guerra debilitó a todos los regímenes políticos, y los imperios continentales se hundieron como consecuencia del esfuerzo que reclamaron de sus súbditos, o como resultado de la derrota. Ello hizo posible que en el más débil y atrasado de ellos, el zarista, la ola de descontento social fuese transformada por Lenin y sus bolcheviques en un régimen alternativo. Para Hobsbswm, este origen signó la historia futura del socialismo en Rusia, y al cabo, en el mundo. Los bolcheviques debieron entonces enfrentar los dilemas de una revolución anticapitalista que reinaba sobre una sociedad diezmada por la guerra, profundamente atrasada y básicamente campesina, y que al mismo tiempo debía competir en un contexto internacional extremadamente hostil. Fueron estos dilemas los que, independientemene de las propuestas político-organizativas provistas por el marxismo, prontamente hicieron que el comunismo soviético tomase la forma de un programa autoritario para modernizar sociedades atrasadas.

En el Oeste, la guerra iba a dejar también enormes secuelas. El arreglo de Versalles ofreció una solución inviable al excluir a Alemania de todo papel en el sistema de poder internacional. La Depresión, en parte ligada a las consecuencias del tratado de paz, fue el siguiente golpe asestado sobre unas sociedades que no se habían recuperado de los traumas de la Gran Guerra. La Depresión no sólo quebró a todas las grandes economías capitalistas y al sistema mundial que las ligaba; para Hobsbawm, al mismo tiempo puso en cuestión la supervivencia de la democracia liberal. En aquellos países en los que la depre- sión se combinó con la crisis de las antiguas clases dominantes y el ascenso de la izquierda organizada, la salida más habitual fue el fascismo.

El fascismo resultó entonces una respuesta a los desafíos de una sociedad en profunda crisis económica y social, al mismo tiempo que amenazada por un movimiento obrero de izquierda poderoso aunque incapaz de hacerse con el poder (como se advierte, Japón y España, entre otros, no ingresan dentro de la categoría, y Hobsbawm prefiere describirlos como regímenes autoritarios). Afirmando una interpretación ya clásica, Hobsbawm ve al fascismo como una reacción a un avance de la izquierda, y por ello sostiene que el mismo encontró su núcleo en la movilización de los sectores medios; si destaca su pertenencia a la era de la política de masas, prefiere en cambio exculpar a las clases populares de toda identificación estricta con el fenómeno en cuestión.

Tras consolidarse internamente y restablecerse de los efectos más dramáticos de la Depresión, los regímenes fascistas y su coro de aliados se lanzaron a una política expansionista que iba a culminar en la Segunda Guerra. Este gran enfrentamiento es considerado por Hobsbawm como el momento decisivo en la historia política del siglo XX. En esos años el enfrentamiento entre capitalismo y comunismo permaneció en un segundo plano, ya que entonces se jugó la suerte de estos dos regímenes que prefiere calificar como hijos de la Ilustración, en abierta batalla contra las fuerzas del fascismo. Por ello, Hobsbawm describe el conflicto como una gran guerra civil a escala internacional, y ello lo obliga a asordinar los componentes nacionales de la resistencia antifascista y de la alianza que finalmente iba a vencer a las fuerzas del Eje.

Paradójicamente, la economía soviética lanzada pocos lustros antes al proceso de industrialización planificada, iba a ser la clave de la derrota de Hitler, y con ella, del reverdecimiento de las democracias liberales occidentales. Pues no sólo el Ejercito Rojo, 
tras detener a las fuerzas alemanas, avanzó de triunfo en triunfo desde Stalingrado hasta Berlin. La experiencia de la economía planificada que estaba sosteniendo materialmente ese avance ofreció inspiración para la planificación indicativa que se colocó en la base de los acuerdos sociales forjados en todo Occidente en la inmediata posguerra. Asimismo, el temor a un avance comunista en una situación de depresión similar a la que sucedió a la Primera Guerra, proveyó incentivos para que el capitalismo se reformara sobre estas líneas socialmente inclusivas.

Ya se ha señalado como Hobsbawm ofrece una explicación en clave social del autoritarismo del modelo soviético, sin vincularlo con el sistema de creencias que se convirtió en ideología oficial de los estados socialistas. Pero Hobsbawm no sólo intenta una recuperación de la tradición de la Segunda Internacional. Asimismo, instala la experiencia soviética como un elemento positivo en la historia del Occidente capitalista. En primer lugar porque enfatiza el papel de los partidos comunistas y el Ejército Rojo en la resistencia y luego en la derrota del fascismo. En segundo lugar, porque sostiene que las grandes reformas de las sociedades capitalistas en la posguerra debieron mucho a los estímulos provenientes de la competencia entre sistemas sociales rivales. Este es un punto especialmente debatible, ya que otros factores - de la economía keynesiana a las experiencias fascistas podrían argumentarse convincentemente como alicientes igualmente poderosos para tales cambios. Esta evaluación de la experiencia comunista está en las antípodas de la ofrecida -también recientementepor Francois Furet en Le passe d' une ilussion (FURET, 1995). Mientras que Hobsbawm prefiere enmarcar esta experiencia en la matriz "progresoreacción”, Furet la coloca, junto a la fascista, como los dos grandes enemigos del mundo liberal y democrático. Si el debate entre estas dos posiciones no tiene visos de cerrarse, al menos puede decirse que ninguna de ellas parece en condiciones de captar la com- plejidad de esas décadas vertiginosas. Pero sin duda con su argumento Hobsbawm encuentra, póstumamente, un sentido insospechado a la experiencia soviética.

En todo caso, tras la Segunda Guerra un capitalismo muy cambiado y con una enorme capacidad de crecimiento y expansión dio lugar a la "Edad de Oro" del siglo, que comprende las décadas que van de la finalización del conflicto a la crisis de comienzos de los años setenta. Hobsbawm es bastante parco para indicar las razones de este gran despegue, y prefire describir como esos años asistieron a transformaciones espectaculares tanto en los países centrales como en la periferia del mundo capitalista. En el centro, las economías desarrolladas, empujadas por la norteamericana, ingresaron desde comienzos de los años cincuenta en una etapa de abundancia y prosperidad nunca antes imaginada, en la que el estado de bienestar apuntalaba al mismo tiempo el proceso de acumulación y la distribución de sus frutos. Es importante señalar que las consecuencias sociales y culturales de esa transformación son decisivas para Hobsbawm, pues a la larga iban a minar las bases sobre las que se asentaba la cohesión política de las clases subalternas, debilitando por tanto aquel factor que en el pasado había sido la principal fuerza de cambio social en Occidente.

En esos años, la declinación de las viejas potencias imperialistas en la periferia apuró el proceso de descolonización, también fomentado por la Unión Soviética y los Estados Unidos, que anhelaban sumar nuevos reclutas a sus áreas de influencia. Un nuevo sistema de estados nominalmente soberanos surgió en Asia y Africa. Muchos de ellos buscaron inspiración en las recetas moscovitas de industrialización y desarrollo, que eran, según Hobsbawm, el principal atractivo que el sistema socialista entonces podía ofrecer a lo que comenzaba a llamarse el Tercer Mundo. Gracias a ellas, o a otras provistas por las economías capitalistas, estas décadas también allí fueron de sostenido cambio. En sociedades hasta entonces agrarias, una transformación cualitativa de la econo- 
mía puso fin al destino campesino o agrícola que habían mantenido por varios miles de años, incluso después de los avances en la mercantilización de la producción agrícola, la fuerza de trabajo o la tierra experimentados en la previa era de expansión imperial. ${ }^{4}$

La Guerra Fría que ensombreció la posguerra tuvo su principal escenario en este terreno recientemente sumado al mundo de los estados soberanos. En Europa, en cambio, Hobsbawm advierte un acuerdo tácito que respetaba las líneas trazadas al finalizar la Segunda Guerra Mundial entre las fuerzas de la Unión Soviética y sus satélites y la alianza liderada por Estados Unidos. Según Hobsbawm, a pesar de la encendida retórica de los contendientes - en especial la apocalíptica que dominó al estado norteamericano los dos aceptaron prontamente que el poder nuclear sólo admitía la coexistencia relativamente pacífica de los sistemas rivales.

Esta situación, aunque recalentada por los conflictos de los años setenta - en Centroamérica, en Afganistán - no iba a ser modificada sino por la inesperada debacle del sistema soviético. La caída de la Unión Soviética es vista por Hobsbawm como un resultado de las dilemas que enfrentaron los reformistas soviéticos cuando se decidieron a iniciar una política destinada a superar el estancamiento de las economías planificadas, que a fines de los años sesenta ya se había tornado evidente. Pues la política de glasnost puesta en marcha por Gorvachev minó la autoridad de la burocracia del estado/partido, el único actor que, a falta de una verdadera sociedad civil, tenía capacidad para liderar y conducir la perestroika que debía vigorizar la vida soviética. El resultado fue la destrucción de los viejos mecanismos que hacían

\footnotetext{
${ }^{4}$ Algunas críticas a este argumento pueden verse en Therborn (THERBORN, 1995, p.88). Consúltense también los comentarios de Tom Nairn (NAIM, 1995) y Michael Mann (MANN, 1995).
}

funcionar a la economía y la sociedad, sin que hubiese alternativa alguna para reemplazarlos.

Cuando el estado soviético entró en crisis, toda su sistema de estados aliados y clientes se quebró sin mayor resistencia. Salvo en Polonia, donde desde comienzos de los años ochenta había surgido una oposición obrera y católica al régimen, en el resto del hinterland soviético los regímenes comunistas se desarmaron sin que enfrentasen desafío organizado alguno. La lección que saca Hobsbawm de los sucesos del Este no ofrece el optimismo de quienes vieron allí un triunfo de la libertad sobre el despotismo, mucho menos de quienes consideraron esa ocasión como una oportunidad para reunir al socialismo con la democracia. La disolución de esos regímenes, que se desfondaron sin fuerte oposición interna, refuerza su idea sobre el carácter limitado de los cambios que sufrieron las sociedades sobre las que reinó la burocracia socialista, así como para argumentar la debilidad de la implantación de las ideologías socialistas oficiales.

El fin de un conjunto de estados nominalmente socialistas cierra el gran conflicto que, salvo en los años de la amenaza fascista, estuvo en el centro de la historia política del siglo. Pero hoy Hobsbawm advierte que el final de esta historia era previsible. Vistas en perspectiva, las circunstancias que dieron lugar al surgimiento del fascismo -la serie de calamidades de la "Era de las Catástrofes", en especial la Gran Guerra y la Depresión Mundial- fueron para Hobsbawm las mismas que hicieron que un sistema social nacido en una periferia atrasada del mundo capitalista pudiese aparecer como una alternativa sustancial a ese orden, ya que le dieron una proyección desproporcionada al poder de los estados socialistas. Una vez que el capitalismo se recuperase -como sucedió en los años de la posguerra- esta situación de competencia no estaba destinada a durar, pues uno de los rivales era indudablemente más poderoso que el otro. Cuando entre esos estados socialistas hoy sólo 
cuenta la China comunista que, bajo el liderazgo de Deng, decidió abrirse a las fuerzas de una expansión capitalista firmemente controlada por un estado nada dispuesto a tolerar disidencias (en términos de Age of Extremes, una especie de perestroika sin glasnost), todo parece indicar que es la dinámica interna de las sociedades occidentales la que signará la suerte de las décadas por venir.

$\mathrm{Y}$ es en estas sociedades que han vivido con el boom de la posguerra la etapa de prosperidad más formidable de toda su historia donde las dos últimas décadas -lo que Hobsbawm llama "El Derrumbamiento"- han dado signos que no alientan su optimismo. Desde comienzos de los años setenta la economía mundial no ha conocido crisis como la del ' 30 , pero parece claro que los mecanismos que la habían hecho crecer de modo armonioso han dejado de funcionar aceitadamente. Los estados nacionales, por su parte, se debilitan, o reformulan los acuerdos sociales de la posguerra. Hoy día, el desempleo y la mendicidad forman otra vez parte del paisaje urbano en cualquier ciudad del occidente desarrollado. Quizá más importante, mientras duró, el sorprendente éxito de los años dorados minó las bases de las solidaridades clasistas que habían actuado hasta ese momento como el principal estímulo para el cambio social: la vieja clase obrera viene perdiendo peso entre los sectores subalternos, las instituciones y tradiciones sobre las que se asentaba su poder se han opacado, minadas por la prosperidad y las tendencias privatizadoras de las sociedades de consumo. Llegado a este punto, Hobsbawm es extremadamente escéptico respecto del potencial de las nuevas fuerzas surgidas de ese ocaso - en especial, del estudiantado y el feminismo - y muy crítico de todas las formas de contestación social nacidas desde los años sesenta.

Considerado en perspectiva, el pesimismo de Hobsbawm se sustenta fuertemente en dos afirmaciones cruciales. Por una parte, que la caída de la Unión Soviética debe evaluarse en términos negati- vos. Este derrumbe contribuye no sólo a la debacle de la economía y la sociedad soviéticas; también desorganiza el sistema de poder mundial, con perceptibles efectos en Europa Oriental, Asia y Oriente Medio. Hay que tener en cuenta que Hobsbawm hace un esfuerzo por señalar que esta caída se produce después de finalizada la Segunda Guerra Fría (un suceso que ve, por cierto, como una iniciativa unilateral de Gorvachev). Por otra parte, Hobsbawm afirma que la dinámica del capitalismo ha adquirido una forma ecológicamente más destructiva y socialmente más excluyente que en el pasado, y - quizá peorincontrolable. Es esta dinámica la que es capaz de infligir severos e irreparables daños en la sociedad, en el medio ambiente.

Por cierto, el colapso repentino de la Unión Soviética y la ausencia de alternativas consistentes a un orden capitalista fuera de control parecen sostener la idea de que una etapa se ha cerrado en la historia del mundo. Y con ello resulta posible volcarse hacia los enfrentamientos y los conflictos de un pasado que hasta hace poco era parte del presente con la sensación de que pertenecen a una época que ya no es totalmente la nuestra. Es esta distancia que no se mide sólo en años la que ahora permite reabrir la pregunta sobre la verdadera clave de nuestra época, y Hobsbawm por momentos ofrece una respuesta desconsoladora, que reconoce en los enfrentamientos sociopolíticos que hicieron vibrar al siglo algo similar a las guerras religiosas medievales. Si es que el conflicto entre sistemas ideológicos rivales no fue más que un conjunto de batallas navales en un vaso de agua, la historia sustancial de nuestra era se ubica en un movimiento de larga duración en el que Hobsbawm destaca el triunfo de la sociedad industrial sobre la agricultura primitiva y el mundo campesino, la explosión demográfica del Tercer Mundo, los cambios en la estructura familiar, entre los sexos y las generaciones.

¿Es esta una victoria inesperada de un modo de considerar la historia en un tiempo identificado con 
una estación en la deriva de la Escuela de Annales? Por muy decisivas que resulten, estas transformaciones - producidas en lo que Goran Therborn ha llamado el nivel de la "geología social" (THERBORN, 1995, p.84), no ocupan el centro de la atención de Hobsbawm. Más bien hacen las veces de telón de fondo y de producto de un proceso histórico ritmado por la combinación de movimientos estructurales y acciones colectivas. $Y$ es desde esta matriz interpretativa que, al revisar la marcha del siglo, a Hobsbawm le resulta difícil hallar en las últimas décadas aquellas perspectivas esperanzadoras que algunos de sus comentaristas, incluso dentro de la tradición de izquierda, encuentran más fácilmente. Como resulta esperable, entre estos últimos se cuentan quienes prefieren otorgar menor relevancia a las características de los procesos de acumulación y a las dimensiones clasistas que siguen siendo tan centrales para Hobsbawm (aunque en Age of Extremes, los primeros ocupan un lugar más destacado que las últimas). Edward Said se halla entre los que han llevado adelante una crítica de este tipo, valorando de muy otro modo los cambios en las actitudes populares desde los años sesenta, enfatizando la autonomía de los procesos sociales en el Tercer Mundo respecto de las fuerzas sociopolíticas de los países centrales, señalando el carácter eminentemente discursivo de las identidades constituídas a lo largo de esta historia (SAID, 1995, p.22-23). Por momentos, la evaluación de uno y otro no puede ser más opuesta. Así, por ejemplo, donde Hobsbawm ve que la "revolución cultural" de la segunda posguerra remata en el triunfo del individuo sobre la sociedad, el autor de Culture and Imperialism advierte en cambio que, al despertar toda una serie de transformaciones en la subjetividad, ella ofrece una renovada fuente de recursos para el cambio social.

En alguna medida, la diferencia entre conclusiones como las de Hobsbawm y Said radica en las distintas evaluaciones que cada uno de ellos hace de los núcleos duros que remiten al marxismo clásico.
En otro sentido, las críticas del intelectual palestino indican que las trayectorias y los compromisos políticos e intelectuales de uno y otro inciden fuertemente en sus consideraciones sobre el momento actual. Por cierto, esta última línea de reflexión nos alerta sobre cómo la mirada de este comunista de toda la vida se identifica con la suerte del proyecto político-institucional que, con la crisis del sistema de estados que lo sostuvo, hoy aparece fenecido, y sobre como ello no puede dejar de pesar en su visión del presente y el futuro. ${ }^{5}$

Teniendo este pesimismo en mente es posible argumentar que el contraste entre la era dorada y el derrumbe que la sucede aparece sobreenfatizado en Age of Extremes. Y ello no sólo porque Hobsbawm tiende a destacar y generalizar las transformaciones producidas entre 1945 y 1973 . También porque presta escasa atención a aquellas señales que evidencian tendencias expansivas en las décadas que suceden a 1973. Entre estas sobresale el formidable desarrollo, económico pero también social, del Oriente. ¿O es que el sorprendente crecimiento de las economías del Sudeste Asiático y el desplazamiento del centro de la economía mundial del Atlántico al Pacífico no ofrece un panorama distinto al de un derrumbamiento en todos los frentes? ¿O es que el incremento en los estándares de vida que de él resulta no indica perspectivas que contrastan con el empobrecimiento y la declinación del sistema soviético, Africa o América Latina? Y no se trata sólo, por cierto, de las nuevas potencias industriales que comenzaron a crecer aceleradamente en los años setenta, como Corea y Taiwan. Se trata también de los países que se han in-

\footnotetext{
${ }^{5}$ El propio Hobsbawm recordaba hace poco que "gran parte de mi vida, probablemente la mayor parte de mi vida adulta, estuvo dedicada (...) a una causa que ha fracasado completamente". Allí mismo señalaba cómo ello contribuyó a definir su visión de la estructura tripartita del siglo que aquí consideramos (HOBSBAWM, 1993, p. 22).
} 
corporado más tarde a esa dinámica de crecimiento, que entre todos suman unos 2.000 millones de habitantes. China crece a una tasa anual acumulativa del $10 \%$ desde hace quince años; en los últimos diez años, ha logrado duplicar -aunque no sin acusadas desigualdades- el ingreso per cápita de su población. Menos espectacular, pero también digno de atención, es lo que sucede en Indonesia, Malasia y la India. Dicho sea de paso, es en la consideración del Oriente -y en menor medida de los Estados Unidos- donde se encuentra el único punto en el que esta historia del siglo queda corta respecto del fin del eurocentrismo que Hobsbawm anuncia como una marca distintiva del siglo. Con relación a otras áreas como el Oriente Medio, la India, América Latina o Africa, y más allá de las esperables críticas del especialista de cada una de estas regiones, ese objetivo se cumple admirablemente.

Al contrastarla con comentarios como el de Said, también se advierte que esa diferencia en las miradas tiene otro origen. Resulta asimismo de las dificultades de Hobsbawm para pensar todo aquello que no parece encuadrarse facilmente dentro de la perspectiva que ofrece la veta racional y progresista que según él recorre la historia occidental, marcando a los actores con los que se identifica, en especial a su clase obrera. En este como en otros textos, Hobsbawm se muestra reacio a entender resultados no previstos dentro de ese patrón de comportamiento, que nuestro siglo ofrece en cantidades abundantes. El impacto de ideologías no específicamente clasistas en las clases populares, en especial del nacionalismo, es uno de ellos. A lo largo de Age of Extremes - al tratar los orígenes de la Primera Guerra Mundial, el ascenso del fascismo o la movilización desatada por la Segunda Guerra Mundial - Hobsbawm lidia no sin dificultad con el punto. Ello resulta de una visión por momentos unilateral del siglo XIX. Pero sin duda el problema mayor es que estas limitaciones para interpretar el siglo XIX se traducen en dificultades para evaluar su complejo legado al siglo XX. El resultado es que, al comparar las dos épocas, Hobsbawm tiende a exagerar el contraste entre uno y otro momento. Ello no sólo ofrece argumentos al pesimismo del autor inglés. Quizá más importante, con ello se debilita su explicación de los motivos que revirtieron las fuerzas que, aunque parecían mover unidireccionalmente al siglo XIX, se opacaron brusca e inesperadamente en el XX.

Se advierte aquí no sólo uno de los aspectos más discutibles de Age of Extremes, sino también uno de los mayores límites del enfoque de Hobsbawm. Estos límites, sin embargo, merecen ser situados. Vale la pena advertir que, más allá de sus dificultades para dar cuenta de ciertos procesos que desafían su visión secular y progresista, la preferencia de Hobsbawm por formas de pensar la historia hoy vistas como poco novedosas debiera evaluarse con atención. Por una parte, es claro que la riqueza de la reflexión de Hobsbawm no es sólo producto de su marxismo, que sigue bajo la marca de perspectivas teóricas tenidas hace tiempo por poco innovadoras incluso dentro de la tradición intelectual de la izquierda británica (SAMUEL Y JONES, 1994, p.X); lo es también de su conocimiento olímpico, de su siempre imaginativa y amplia curiosidad histórica, de su destreza para la generalización, de su agudeza para destacar el detalle sugestivo. Todas estas capacidades muy bien pueden desarrollarse en el marco de otras tradiciones de investigación. Pero en todo caso, resulta destacable que haya sido en el marco de un pensamiento matrizado por perspectivas que señalan la globalidad y unidad de lo social, y las dimensiones estructurales y fuertemente determinadas de los procesos históricos, que Hobsbawm haya logrado producir la mejor síntesis de nuestro siglo de que por ahora disponemos. Y si es que la problemática de una historia mundial todavía conserva su legitimidad y su vigencia, poco parece indicar que el rechazo de perspectivas como la de Hobsbawm resulte capaz de ofrecer, a cambio, una propuesta alternativa para interpretar los problemas generales de nuestro 
siglo XX. El impacto de la restructuración capitalista en curso, tanto en las metrópolis como en las periferias, por ejemplo, parece indicar la justeza de aquellas afirmaciones que destacan la unidad de este proceso, así como su centralidad para moldear los destinos colectivos. Más en general, resulta difícil pensar en otros principios capaces de articular una narrativa cuyo alcance explicativo resulte igualmente amplio y convincente. Aun cuando se discrepe con la visión pesimista que Hobsbawm hace suya, el historiador inglés no parece no haber errado al afirmar que

\section{Bibliografía:}

ANDERSON, "Perry. Darkness falls". Guardian, 8 nov 1994. CORRIGAN, Philip. "On the Politics of Production: A Comment on 'Peasants and Politics' by Eric Hobsbawm'. Journal of Peasant Studies, 2 (3), 1975.

FURET, Francois. Le passe d'une ilussion. Paris, Robert Laffont, 1995. HOBSBAWM, Eric J. "Problèmes agraires à la Convención". Les problèmes agraires des Amèriques Latines. Paris, CNRS, 1967. "Peasant and Rural Migrants in Politics". in VÉLIZ, Claudio (compilador). The Politics of Conformity in Latin América. Oxford, OUP, 1967.

"A Case of Neo-Feudalism: La Convención, Perú". Journal of Latin American Studies, vol. I, 1969.

"Peasant Land Occupations". Past and Present, n.62, 1974, p. 120-52.

"Peasant Movements in Colombia". International Journal of Economic and Social History, vol. VIII, 1976 "The Present as History: Writing the History of One's Own Times". The Creighton Lecture, London, University of London Press, 1993.

"Age of Extremes. The Short Twentieth Century 19141991. Abacus, 627p. 1995 (primera edición, 1994). el siglo XX, a su modo, también está pautado por la expansión de la sociedad capitalista, y por las transformaciones y conflictos que su avance ha generado. En todo caso, y más allá de las limitaciones del magnífico Age of Extremes, una cosa es segura: Hobsbawm ha colocado la discusión sobre el sentido de nuestra época en una posición bien elevada. Es de esperar que quienes se internen en su espesura lo hagan con la inquietud y la amplitud de miras que signa la trayectoria de este historiador que sigue haciendo del pasado un instrumento de comprensión del presente.

MANN, Michael. "As the Twentieth Century Ages". New Left Review, n.214, nov./dec. 1995, p.104-24.

NAIRN, Tom. "Breakwaters of 2000: From Ethnic to Civic Nationalism". New Left Review, n.214, nov/dec.1995, p.91-105.

THERBORN, Goran. "The Autobiography of the Twentieth Century". New Left Review, n. 214, nov/dec.1995, p.81-90.

JUDT, Tony. "Downhill All the Way". New York Review of Books, 25 may 1995, p.20-5.

KANE, Harvey. The British Marxist Historians. Cambridge y Oxford: Polity Press, 1984.

McCLELLAND, Keith. "Bibliography of the Writings of Eric Hobsbawm". en Samuel, Raphael y Jones, Gareth Stedman (compiladores). Culture, Ideology and Politics. Essays for Eric Hobsbawm. London: History Workshop Series, 1983.

SABATO, Hilda. "Hobsbawm y nuestro pasado". Punto de Vista, n.46, 1993, p.13-17.

SAID, Edward. "Contra Mundum". London Review of Books, 9 may 1995, p.22-23.

SLATTA, Richard W. (editor). The Varieties of Latin American Banditry. New York y Londres: Greenwood, 1987.

Endereço do Autor: Domicilio entre el 20/09/1996 y el 20/04/1997: Bonpland 2348 5 D • $1425 \bullet$ Buenos Aires • Argentina • Tel: 541775-7083 • E-mail: rhora hisrav.filo.uba.ar • Domicilio permanente: St Antony’s College Oxford • OX2 6JF • United Kingdom • Fax: 44-01865-310518 • E-mail: roy.hora sant.ox.ac.uk 